Original articles

\title{
Long term variation of an amphipod species' population secondary production as indicator of incomplete resilience in a temperate estuary
}

\author{
Nuno Leite*, Alexandra Guerra, Alda Almeida ${ }^{1}$, João Carlos Marques, Irene Martins \\ IMAR - Institute of Marine Research, Marine and Environmental Research Centre (IMAR-CMA), c/o Department of Life Sciences. Faculty of Sciences and \\ Technology, University of Coimbra, 3004-517 Coimbra, Portugal
}

\section{A R T I C L E I N F O}

\section{Article history:}

Received 24 April 2013

Received in revised form 29 July 2013

Accepted 2 August 2013

\section{Keywords:}

Amphipods

Estuary

Incomplete resilience

Population dynamics

Production

\begin{abstract}
A B S T R A C T
During the last decades many estuaries underwent ranges of environmental pressure due to increasing anthropogenic pressures and the undertaken of mitigation measures to prevent the impoverishment of these areas. The Mondego estuary (NW Atlantic coast of Portugal), a mesotidal shallow estuary, is one typical case of this. In the 1980s, the system was characterized by rich and stable animal and vegetal communities, with no eutrophication symptoms (pre-eutrophication period), whereas during the 1990s, massive seasonal macroalgal blooms were observed and the concomitant adverse consequences on the system's biodiversity were registered (eutrophication period). More recently (2000-2010), eutrophication symptoms have gradually decreased due to several mitigation actions, whilst recent studies indicate that the system is recovering in terms of biodiversity and structure (post-mitigation period). The population dynamics and productivity of Echinogammarus marinus (Leach) (Amphipoda, Gammaridae), a key species associated to fucoids in many Northern Atlantic estuaries, was analyzed and compared throughout these three distinct periods in the Mondego estuary, using data collected between April 2009 and March 2010 and data from the 1980s (pre-eutrophication) and 1990s (eutrophication period). The goal of this study was to test if the long-term variation of E. marinus would somehow reflect the range of environmental conditions observed in the system from the 1980s until 2010. Results showed that, in the three different periods, the species exhibited higher densities during spring, with continuous sexual activity throughout the year, multivoltine life cycle and seasonal sex-ratio fluctuations. Moreover, salinity was a major factor affecting the amphipod population in all three periods. On the other hand, differences related to the production of E. marinus were detected, being clearly higher in the $1980 \mathrm{~s}$ (pre-eutrophic period), followed by the last decade (post-mitigation period) and, finally, the 1990s (eutrophication period), where population production and density values were the lowest of all three periods. These results suggest that E. marinus production parameters reflected the decline in environmental conditions during the 1990s, as well as the partial recovery resulting from the application of mitigation measures, exhibiting a good sensitivity to environmental pressures, namely eutrophication. Therefore, we propose that in the last years, the Mondego estuary has been under an incomplete resilience period, characterized by some environmental improvement compared to the 1990s but still distant from the 1980s condition. Overall, $E$. marinus production parameters seem to be good indicators of the system's environmental condition and might be useful regarding monitoring programmes in most Northern Atlantic estuaries.
\end{abstract}

(C) 2013 Elsevier Ltd. All rights reserved.

\section{Introduction}

Estuaries are dynamic systems exhibiting variations on their environmental status and functional properties over time (e.g. Kemp et al., 2005). These variations reflect the system intrinsic variance, the effects of anthropogenic pressures and/or other types of

\footnotetext{
* Corresponding author. Tel.: +351913776548.

E-mail addresses: nleite@student.uc.pt, nleite4@gmail.com (N. Leite).

1 Deceased.
}

pressures, and the system's own resistance and resilience to disturbance. Estuaries are also characterized by relatively few species but with abundant populations that can be highly productive in natural conditions, making it difficult to dissociate anthropogenic from natural stress (Elliott and Quintino, 2007; Dolbeth et al., 2011).

In the last decades, many studies have reported the occurrence of eutrophication and other environmental problems in estuaries (Flindt et al., 1997; Hernandez et al., 1997; Kemp et al., 2005), however, the proper assessment of variation and evolution of the system's state can only be carried out with long-term data series (e.g. Dolbeth et al., 2011). 
Natural ecosystems have the ability to recover from anthropogenic perturbations, whether by natural restoration or assisted by human intervention and can return to the pre-existing condition or to an alternate state (sensu SER, 2002; Elliott et al., 2007; Borja et al., 2010). Essentially, this ability to recover from a given pressure is defined by resilience (MarLIN Glossary, 2005) and the degree of recovery will allow the return to the original state - complete resilience - or to a different state - partial or incomplete resilience (Elliott et al., 2007).

However, resilience has been defined in many ways by different disciplines. From an engineering point of view, resilience is the resistance to disturbance and speed of return to a predefined equilibrium steady state (Holling et al., 1995; Pimm, 1984). From the biological perspective, resilience is the amount of disturbance that can be absorbed before a system's ability to maintain its structure and behaviour patterns is compromised (Holling et al., 1995). Other definitions of ecological resilience emphasize the speed of recovery from a disturbance, highlighting the difference between resilience and resistance, where the latter is the extent to which disturbance is actually translated into impact (Adger, 2000). Adger (2000) also relates resilience of an ecological system to its functioning, rather than the stability of its component populations, or even the ability to maintain a steady ecological state. Indeed, coastal and estuarine systems are considered highly resilient because of their high levels of functional diversity, despite their low species diversity (Costanza et al., 1995). In this paper we apply Elliott et al. (2007) definition of resilience (described above) and use an amphipod's functional parameters (e.g. productivity, density) as a proxy for the system's resilience between periods without significant environmental pressure (pre-eutrophic), with significant environmental pressure (highly eutrophic) and following the application of mitigation measures (post-mitigation).

The Mondego estuary, a shallow mesotidal estuary from the Atlantic coast of Portugal, has been monitored since the 1980s until today. The system has changed from a low-environmentallyimpacted estuary during the 1980s, becoming strongly eutrophic during the 1990 s, to a partially recovered system at the present (Martins et al., 2001; Marques et al., 2003; Dolbeth et al., 2011; Veríssimo et al., 2012).

Echinogammarus marinus (Leach, 1815) is a gammarid amphipod that occurs from Norway to Portugal where the Mondego estuary (Western Coast of Portugal) has been indicated as the southernmost limit of its known distribution (Maren, 1975a, 1975b; Marques and Bellan-Santini, 1993). In this estuary E. marinus is a key species in the algal covered habitats namely in Fucus spp., presenting extensive distribution, high abundances (Marques and Nogueira, 1991; Maranhão et al., 2001) and is considered as an important prey to the upper trophic levels, especially birds (Múrias et al., 1996, 1997).

Two studies on E. marinus population dynamics in the Mondego estuary were previously carried out, one in the 1980s (Marques and Nogueira, 1991) and the other in the 1990s (Maranhão et al., 2001), covering different periods in terms of the system's ecological condition. In the 1980 s the estuary was not obviously eutrophic while in the 1990s massive green macroalgae blooms, a typical eutrophication symptom occurred frequently.

Results from the first study revealed a population density ranging from 96 to 3921 ind $\mathrm{m}^{-2}$, with the highest abundances occurring during spring and summer. Sexual activity was found to be continuous throughout the year but recruitment almost stopped in early winter. E. marinus lifespan was estimated at 10-12 months and growth production ranged from 6.36 to $8.81 \mathrm{~g} \mathrm{AFDW} \mathrm{m}^{-2} \mathrm{y}^{-1}$. The life cycle was found to be multivoltine, with iteroparous females and high individual fecundity, revealing an $r$ adaptive strategy (Marques and Nogueira, 1991).
In the study from the 1990s abundances also reached the highest values during spring, however, the density range $18-613$ ind $\mathrm{m}^{-2}$ - was clearly lower than those recorded in the 1980s study and on average annual production in the 1990 s was considerably lower than in the 1980s $\left(1.74-5.38 \mathrm{~g} \mathrm{AFDW} \mathrm{m}^{-2} \mathrm{y}^{-1}\right)$. As in the previous study, the population was found to be sexually active throughout the year but, contrarily to the previous study, it decreased but did not stop in early winter. Maranhão et al. (2001) considered the decrease in abundance and production occurred through a decade mostly as a response to increasing anthropogenic pressure (e.g. dredging activities and eutrophication) in the Mondego estuary.

Given the importance of E. marinus in the Mondego estuary trophic structure and functioning, the goal of this study was to assess if the long-term variation of this species population parameters could reflect the range of environmental pressure observed in the system from the 1980s until 2010, namely regarding its response after the application of eutrophication mitigation measures from the end of the 1990s.

\section{Materials and methods}

\subsection{Study area}

The Mondego estuary $\left(40^{\circ} 08^{\prime} \mathrm{N}, 8^{\circ} 50^{\prime} \mathrm{W}\right)$ is located on the Atlantic coast of Portugal and consists of two arms, North and South, with distinct characteristics. The South arm is shallower and richer in terms of biodiversity, while the North arm is deeper, with a higher freshwater input from the Mondego River and constituting the main navigation channel (Marques et al., 1993a, 1993b; Dolbeth et al., 2003). Both arms of the estuary present hard substrates in the intertidal area, primarily covered by Fucus spp. which constitutes an eulitoral macroalgal belt that comprises up to $60 \%$ of the estuarine banks (Marques and Nogueira, 1991). For a more complete description of the Mondego estuary see Cardoso et al. (2004) and Marques et al. (2013).

Prior to 1985 there were no reference studies on the Mondego estuary, however, in the late 1980s the Mondego estuary was described as having a severe increase of environmental stress mainly due to human activities. Physical disturbance occurred mostly on the North arm where biodiversity and structure of macrobenthic communities was lower, whereas in the South arm the macrofaunal abundance and biodiversity was higher, especially in the Zostera noltii meadows, an important primary producer in the estuary (Marques et al., 1993a, 1993b). Although the South arm was less impacted by human activities, significant macroalgal blooms led to eutrophication problems and by the end of the 1980s and early 1990s the area occupied by $Z$. noltii was reduced from 15 ha to 1.6 ha (Cardoso et al., 2004; Verdelhos et al., 2005).

During the 1990s, the anthropogenic pressures in the estuarine system became even more accentuated. The communication between both arms was interrupted (1994-1995) in order to regularize the main navigation channel (North arm) which almost ceased the supply of freshwater from the Mondego River to the South arm (Marques et al., 2003). Consequently, the water residence time became higher in the South arm, allowing the deposition of sediments, higher residence time of dissolved nutrients, higher salinities, as well as decreasing light extinction coefficients in the water column. These conditions favoured the occurrence of macroalgal blooms, especially of Ulva spp. (Flindt et al., 1997; Marques et al., 1997, 2003; Lillebø et al., 1999; Duarte et al., 2001; Martins et al., 2001) and the reduction of the area occupied by $Z$. noltii, which reached a minimum value of 0.02 ha in 1997 (Cardoso et al., 2008b). In 1998, several mitigation measures were implemented and gradually allowed for the system's recovery from the effects of eutrophication, e.g. density and biomass increase in 
key species Hediste diversicolor and Scrobicularia plana (Cardoso et al., 2010). The most important measures were (1) the partial re-establishment of the connection between both arms, improving freshwater circulation and reducing the nutrient load; (2) rerouting most of the Pranto River nutrient enriched freshwater to the North arm, leading to nutrient loading reduction into the South arm and (3) physical protection of the seagrass beds from human disturbance (Cardoso et al., 2005; Lillebø et al., 2005; Neto et al., 2010; Dolbeth et al., 2011).

During the last decade, the Mondego estuary continued to suffer important anthropogenic impacts related to tourism, harbour activities, aquaculture and agriculture from the upstream rice farms (Pinto et al., 2010). However, the mitigation measures implemented in the late 1990s seem to have been partially effective, since the nutrient load was reduced, shown by the decrease of dissolved inorganic nitrogen by $40-50 \%$ and no extensive macroalgal blooms were recorded ever since (Cardoso et al., 2010). This allowed the $Z$. noltii meadows to recover, at least in spatial extent ( 4.7 ha in 2006), although biomass $\left(\approx 100 \mathrm{~g} \mathrm{AFDW} \mathrm{m}^{-2}\right)$ is still much lower than in $1993\left(\approx 250 \mathrm{~g} \mathrm{AFDW} \mathrm{m}^{-2}\right)$ but with positive impacts on the macrobenthic community structure (e.g. considerable increase in production of slow-growing species such as S. plana and $\mathrm{H}$. diversicolor) (Dolbeth et al., 2011). In 2006, the complete re-establishment of the communication between both arms of the Mondego estuary occured, ending a series of mitigation measures in the estuary (Marques et al., 2007; Veríssimo et al., 2012). Extreme climate events have also occurred during the last decade, for instance, a major flood came about in the winter of 2000/2001 and heat waves were recorded in 2003 and 2005, the latter accompanied by a severe drought (Neto et al., 2010; Dolbeth et al., 2011), which had negative impacts especially on the South arm macrobenthic communities, such as $Z$. noltii biomass decrease after heatwaves and Hydrobia ulvae an S. plana production decline after the floods and severe drought (Cardoso et al., 2008a, 2008b; Dolbeth et al., 2011), however, no significant events have been recorded ever since in the Mondego estuary.

\subsection{Field and laboratory methodology}

Sampling took place from April 2009 to March 2010 at three sampling stations: S1, located in the North arm of the Mondego estuary, upstream from the Figueira da Foz harbour, S2, located in the South arm at the mouth of the Armazéns channel and S3, also in the South arm, upstream from S2, at the confluence of the Pranto river (Fig. 1).

Three replicates at the Fucus spp. algal cover were monthly collected at each sampling station during low tide. Since the sampled surface was often irregular, the area covered by Fucus spp. was estimated by projecting its shape to a polyethylene surface which was later weighed for weigh-area conversion, according to significant regressions (see Marques and Nogueira, 1991). Each sample was obtained by scraping the rocky surface where the algae were attached. In addition, the superficial $2 \mathrm{~cm}$ layer within the selected area was also collected to reduce the escape of organisms, washed in situ using a $0.5 \mathrm{~mm}$ nylon mesh bag and preserved in $4 \%$ buffered formalin for posterior sorting. The Fucus spp. portion was placed inside identified plastic bags and taken to the laboratory where it was carefully washed with tap water to collect all E. marinus and other organisms, and immediatly weighed for fresh weight $(\mathrm{g})$ determination. Several samples of Fucus spp. were dried in a stove at $60^{\circ} \mathrm{C}$ for at least $72 \mathrm{~h}$ in order to obtain a fresh weight - dry weight regression, and afterwards burned at $450^{\circ} \mathrm{C}$ in a muffle for $8 \mathrm{~h}$, to determine the ash free dry weight (AFDW). Temperature, salinity, dissolved oxygen (\% and mg. $\mathrm{L}^{-1}$ ) and $\mathrm{pH}$ were measured in situ at each sampling station in low water retention pools. Additionally, water samples were collected to determine the dissolved content of nitrogen $\left(\mathrm{N}-\mathrm{NO}_{2}, \mathrm{~N}-\mathrm{NO}_{3}, \mathrm{~N}-\mathrm{NH}_{3}\right)$, and phosphorus $\left(\mathrm{P}-\mathrm{PO}_{4}\right)$ and sediment samples were collected to estimate its organic matter content. Nutrient analysis was performed according to the standard methods described in Limnologisk Metodik (1992) for ammonia (N$\mathrm{NH}_{3}$ ) and phosphate ( $\left.\mathrm{P}-\mathrm{PO}_{4}\right)$, and in Strickland and Parsons (1972) for nitrate $\left(\mathrm{N}-\mathrm{NO}_{3}\right)$ and nitrite $\left(\mathrm{N}-\mathrm{NO}_{2}\right)$ whereas sediment samples were dried in a stove at $60^{\circ} \mathrm{C}$ for $72 \mathrm{~h}$ and then burned in a muffle at $450{ }^{\circ} \mathrm{C}$ for $8 \mathrm{~h}$.

\subsection{Data analysis}

The density $(D)$ of $E$. marinus in the algae cover (number of individuals. $\mathrm{m}^{-2}$ ) was related with both sampled area and algal density through the formula:

$D=A x B$

where $A$ is the number of amphipods per gram of algae in each sample and $B$ is the average weight of algae $(\mathrm{g})$ per square metre on a sample date (Marques and Nogueira, 1991).

To estimate biomass, total length $\left(T_{L}\right)$ and weight $(W)$ of the $E$. marinus individuals were calculated from cephalic length measures according to the equations previously determined by Marques and Nogueira (1991), respectively:

$T_{L}=-1.211995+10.668590 C_{L}$

$W=1.592924 x C L^{3.94344}$

where $W$ refers to ash-free dry weight (mg AFDW) and $C_{L}$ is the cephalic length ( $\mathrm{mm})$.

Secondary production was calculated by applying the sum of size frequency technique (posterior to Krueger and Martin, 1980), modified to estimate the production in intervals between samples (Grémare et al., 1989). This method implies quantifying the number of individuals from each size class in each sampling date, and production is given by the sum of the biomass increments of different size classes for a given period:

$$
\begin{aligned}
P= & \sum_{j=1}^{a-1} 0.5\left[\left(Y_{i, j}+Y_{i+1, j}\right)-\left(Y_{i, j+1}+Y_{i+1, j+1}\right)\right] \\
& \times\left(W_{j} \times W_{j+1}\right) 0.5 \times(t)^{-1}
\end{aligned}
$$

where $P$ is the production rate, $Y_{i, j}$ is the mean density (ind $\mathrm{m}^{-2}$ ) of the size class $j$ on the date $i, W_{j}$ is the biomass $\left(\mathrm{g} \mathrm{m}^{-2}\right)$ of the size class $j$ and $t$ stands for the time (in days) between the dates $i$ and $i+1$.

\subsection{Statistical analysis}

Density and biomass data were analyzed through a factorial PERMANOVA (significance level of $\alpha=0.05$; 999 permutations) to check for significant differences between stations (S1, S2 and S3) and seasons (spring, summer, autumn and winter). Pair-wise tests (significance level of $\alpha=0.05$; 999 permutations) were performed to discriminate the differences within the levels of each factor. Physicochemical data were analyzed through a principal component analysis (PCA), to test which variables contributed for the variation between sampling stations and seasons. The relationships between variation of environmental variables and biological parameters (density and biomass) of E. marinus were explored through a distance based linear model (DistLM), with "Best" as the selection procedure and "AICc" as the selection criterion. A distance based redundancy analysis (dbRDA) was performed to have a representation of the model in the multivariate space. All data was analyzed with PRIMER-E's software PRIMER 6+ PERMANOVA ${ }^{\circledR}$ (software package from Plymouth Marine Laboratory, UK) (Clarke and Warwick, 2001; Anderson et al., 2008). 


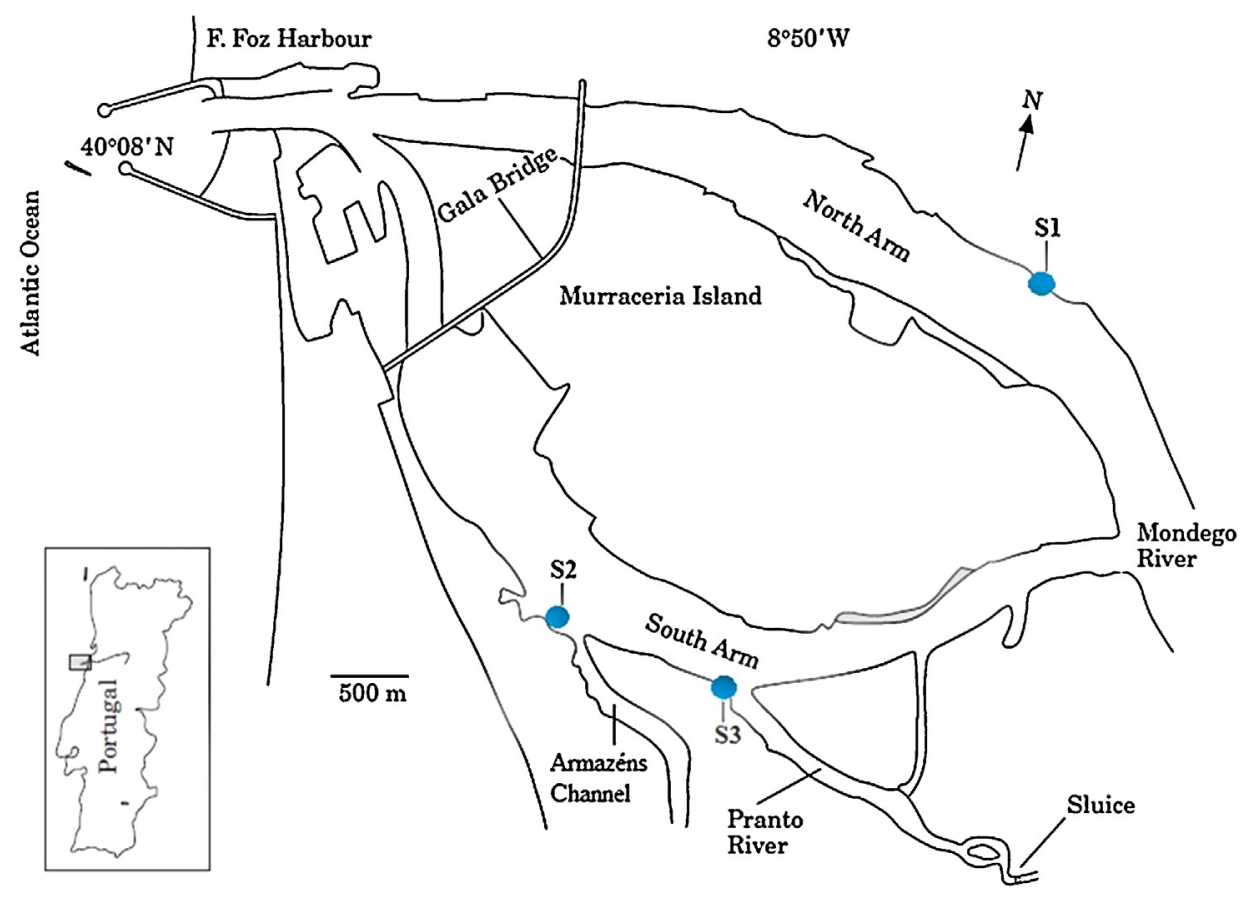

Fig. 1. Location of the sampling stations at the Mondego estuary: S1 in the north arm and S2 and S3 in the south arm.

\section{Results}

\subsection{Density and biomass}

E. marinus density (Fig. 2A) presented seasonal variations with a spring peak (April 2009 in S2 and S3; May 2009 in S1), followed
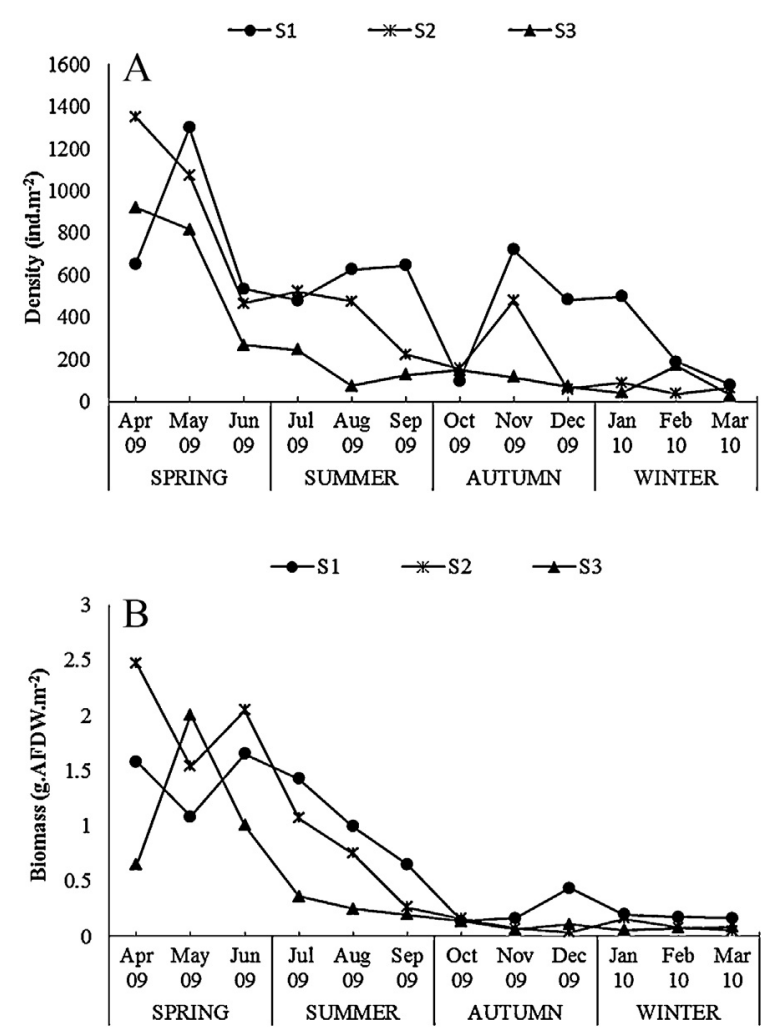

Fig. 2. E. marinus density (A) and biomass (B) variation at the three sampling stations during the study period. by a gradual decrease throughout the study period up to March 2009. A smaller autumn peak also occurred but only in S1 and S2 (November 2009). Spatially, S1 presented higher abundances during most of the sampling period $\left(524.8\right.$ ind $\left.\mathrm{m}^{-2}\right)$, while lower values were almost always registered in S3 (252.2 ind $\mathrm{m}^{-2}$ ) and intermediate values in $\mathrm{S} 2\left(415.6\right.$ ind $\left.\mathrm{m}^{-2}\right)$.

Biomass (Fig. 2B) also showed higher values during spring, in all stations and then decreased until the end of the study period. $\mathrm{S} 1$ and S2 averaged similar biomasses $\left(0.72 \mathrm{~g} \mathrm{AFDW}^{-2}\right)$ while S3 presented lower biomasses $\left(0.42 \mathrm{~g} \mathrm{AFDW}^{-2}\right)$.

Regarding group population density, juveniles were always more abundant at all sampling stations and almost always corresponded to more than $50 \%$ of the population, except in February and March 2010 (43 and 40\%, respectively). Males and females occurred in similar percentages although slightly higher in males (19 and $17 \%$, respectively). In general, males presented higher biomasses $\left(0.35 \mathrm{~g} \mathrm{AFDW} \mathrm{m}^{-2}\right)$ followed by females $\left(0.20 \mathrm{~g} \mathrm{AFDW}^{-2}\right)$ and juveniles $\left(0.06 \mathrm{~g} \mathrm{AFDW} \mathrm{m}^{-2}\right.$ ).

Statistical analysis exhibited spatial and temporal differences for both E. marinus density and biomass. Density was significantly different between sampling stations $(\mathrm{F}(\mathrm{St}) 2,24=7.6717 ; p=0.002)$ and seasons $(\mathrm{F}(\mathrm{Se}) 3,24=15.668 ; p=0.001)$, with pair-wise tests demonstrating that S1 (North arm) was different from the other sampling stations, although S2 and S3 (South arm) were not statistically different from each other and that all seasons are dissimilar from each other. Biomass showed similar results with significant differences between sampling stations $(\mathrm{F}(\mathrm{St}) 2,24=4.8907 ; p=0.01$ ) and seasons $(\mathrm{F}(\mathrm{Se}) 3,24=27.91 ; p=0.001)$, with pair-wise tests also demonstrating that only S1 was different from the other two stations and that all seasons were distinct apart from autumn and winter.

\subsection{Reproduction and sex-ratio}

E. marinus sexual activity was inferred from the percentage of ovigerous females in relation to the total number of females and the proportion of juveniles in the total population, with our data indicating that sexual activity was continuous during the study period 


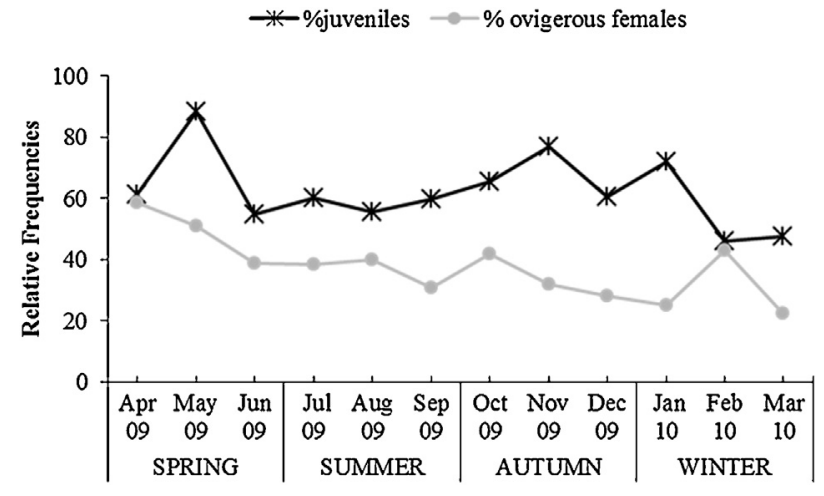

Fig. 3. Relative frequencies of juveniles and ovigerous females throughout the study period.

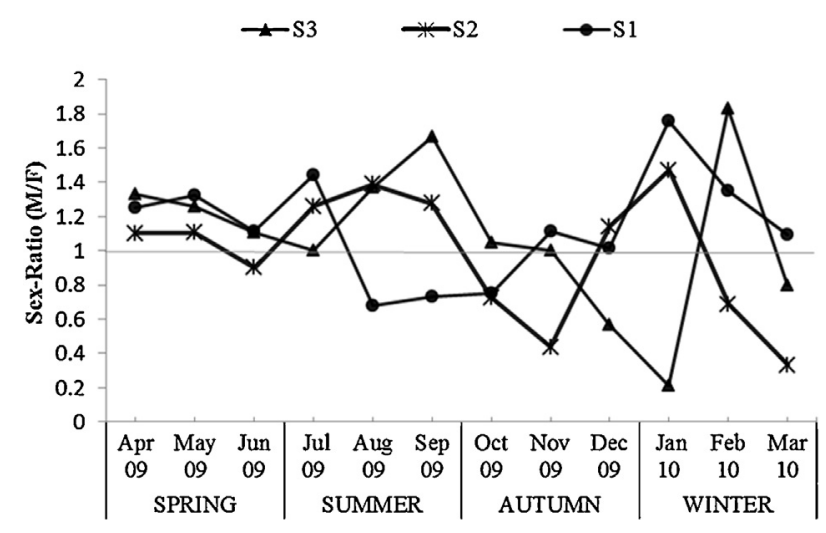

Fig. 4. E. marinus sex-ratio at the three sampling stations during the study period.

at all sampling stations, although it almost ceased during winter in S1 and by the end of the winter in S3 (Fig. 3).

Generally and as expected, the relative frequency of juveniles was higher after periods of high frequencies of ovigerous females. In fact, the highest percentage of juveniles (96\%) occurred at S1 in May 2009 after the highest percentage of ovigerous females was observed in April 2009 (71\%). During the study period, S2 and S3 averaged higher percentages than S1 for ovigerous females $(41 \%$, $38 \%$ and $34 \%$, respectively) and juveniles (64\%, $62 \%$ and $60 \%$, respectively).

Sex-ratio showed oscillations during the study period, being nevertheless predominantly favourable to males in all stations (Fig. 4). In S1, sex-ratio was favourable to males most of the sampling period, shifting only to female dominance during summer and early autumn. In S2, a major shift to female dominance occurred during autumn, changing back to male dominance by the end of autumn and early winter and shifting again to female prevalence during winter and until the end of the study. The pattern in S3 was mostly identical to the one observed in S2, but with a month's delay.

Table 1

Echinogammarus marinus production values and $P / \bar{B}$ ratios at the three sampling sites.

\begin{tabular}{llll}
\hline & $P\left(\mathrm{~g} \mathrm{AFDW} \mathrm{m}^{-2} \mathrm{y}^{-1}\right)$ & $\bar{B}\left(\mathrm{~g} \mathrm{~m}^{-2}\right)$ & $P / \bar{B}$ \\
\hline S1 & 5.78 & 0.72 & 8.03 \\
S2 & 6.35 & 0.72 & 8.82 \\
S3 & 2.11 & 0.42 & 5.02 \\
\hline
\end{tabular}

\subsection{Production}

Annual production (Table 1) was higher in S2 $\quad\left(6.35 \mathrm{gAFDW} \mathrm{m}^{-2} \mathrm{y}^{-1}\right)$, followed closely by S1 (5.78 $\left.\mathrm{g} \mathrm{AFDW} \mathrm{m}^{-2} \mathrm{y}^{-1}\right)$, whereas $\mathrm{S} 3$ presented the lowest average annual production $\left(2.11 \mathrm{~g} \mathrm{AFDW}^{-2} \mathrm{y}^{-1}\right)$. As for $P / \bar{B}$ ratios, they were very similar between S1 and S2 (8.03 and 8.82, respectively) while S3 showed the lowest value (5.02).

\subsection{Environmental factors}

Throughout the study period, the physicochemical parameters displayed temporal and spatial differences $(\mathrm{F}(\mathrm{Se}) 2.24=4.6586$; $p=0.001$ and $\mathrm{F}(\mathrm{St}) 3.24=3.4874 ; p=0.001$, respectively). As expected in a temperate estuary, both water temperature and salinity reached maximum values during summer and minimum during winter, in both arms of the estuary $\left(5.4-31.7^{\circ} \mathrm{C}\right.$ and $2.6-36.5^{\circ} \mathrm{C}$ at the North and South arms, respectively) (Fig. 5A and B). Dissolved oxygen concentration reached the highest values in spring at all sampling stations and S1 frequently displayed higher values of dissolved $\mathrm{O}_{2}$ while $\mathrm{S} 3$ presented lower values (Fig. 5C). The pH values showed considerable oscillations during spring and summer, stabilizing during autumn and winter, with S1 presenting higher values during most of the sampling period (Fig. 5D). Dissolved phosphate concentrations remained relatively stable throughout the study period apart from an autumn peak in S3 and a winter peak at all sampling sites (Fig. 6A). Dissolved nitrogen in the form of ammonia clearly oscillated in the South arm, with autumn and winter peaks in S3 and S2, respectively (Fig. 6B), while nitrite and nitrate concentrations showed seasonal variation, reaching the highest values during autumn and winter in all sampling stations (Fig. 6C and D). Concerning the organic matter content of the sediment, S2 presented a higher content, averaging 3.25\% $( \pm 1.05)$, S3 averaged $2.79 \%( \pm 1.22)$ and S1 (North arm) registered lower values, with an average of $1.71 \%( \pm 0.83)$ (Fig. 6E).

PCA analysis accounted for $60.4 \%$ of the total variation (PC1 and PC2) where the first axis of variability showed that spring and summer samples were characterized by higher values of salinity and water temperature and lower values of nitrites and nitrates, whereas winter samples were characterized by higher values of nitrites and nitrates and lower values of water temperature and salinity (Fig. 7A). The second axis of variability, although less significant, shows that North arm (S1) samples were characterized by higher values of $\mathrm{pH}$ and dissolved $\mathrm{O}_{2}$ as opposed to most samples from the South arm (S2 and S3) (Fig. 7B).

The DistLM analysis for density showed a best solution (AICC $=214.01 ; R^{2}=0.52$ ) that included four variables: salinity, dissolved oxygen, ammonia concentration and phosphate concentration. To visualize the regression model in a constrained ordination, a distance based redundancy analysis (dbRDA) was performed, which resulted in a two dimensional plot where the first axis explains $49.2 \%$ of the total variation (Fig. 8). The same analysis for biomass resulted in a best solution ( $\mathrm{AICC}=192.39 ; R^{2}=0.36$ ) that included two variables, salinity and ammonia concentration.

\subsection{Previous studies}

A comparison between the previous studies on E. marinus population dynamics in the Mondego estuary and our study is summarized in Table 2. Our data $\left(40-1400\right.$ ind $^{-2}$ ) shows an increase in density since the 1990 s period $\left(25-700\right.$ ind $\mathrm{m}^{-2}$ ) that still comes up short from the values described in the 1980 s period (500-4000 ind $\mathrm{m}^{-2}$ ).

Production values (2.11-6.35 $\mathrm{g} \mathrm{AFDW} \mathrm{m}^{-2} \mathrm{y}^{-1}$ ) were also higher than the 1990s study $\left(1.74-5.38 \mathrm{~g} \mathrm{AFDW} \mathrm{m}^{-2} \mathrm{y}^{-1}\right)$ but lower than 

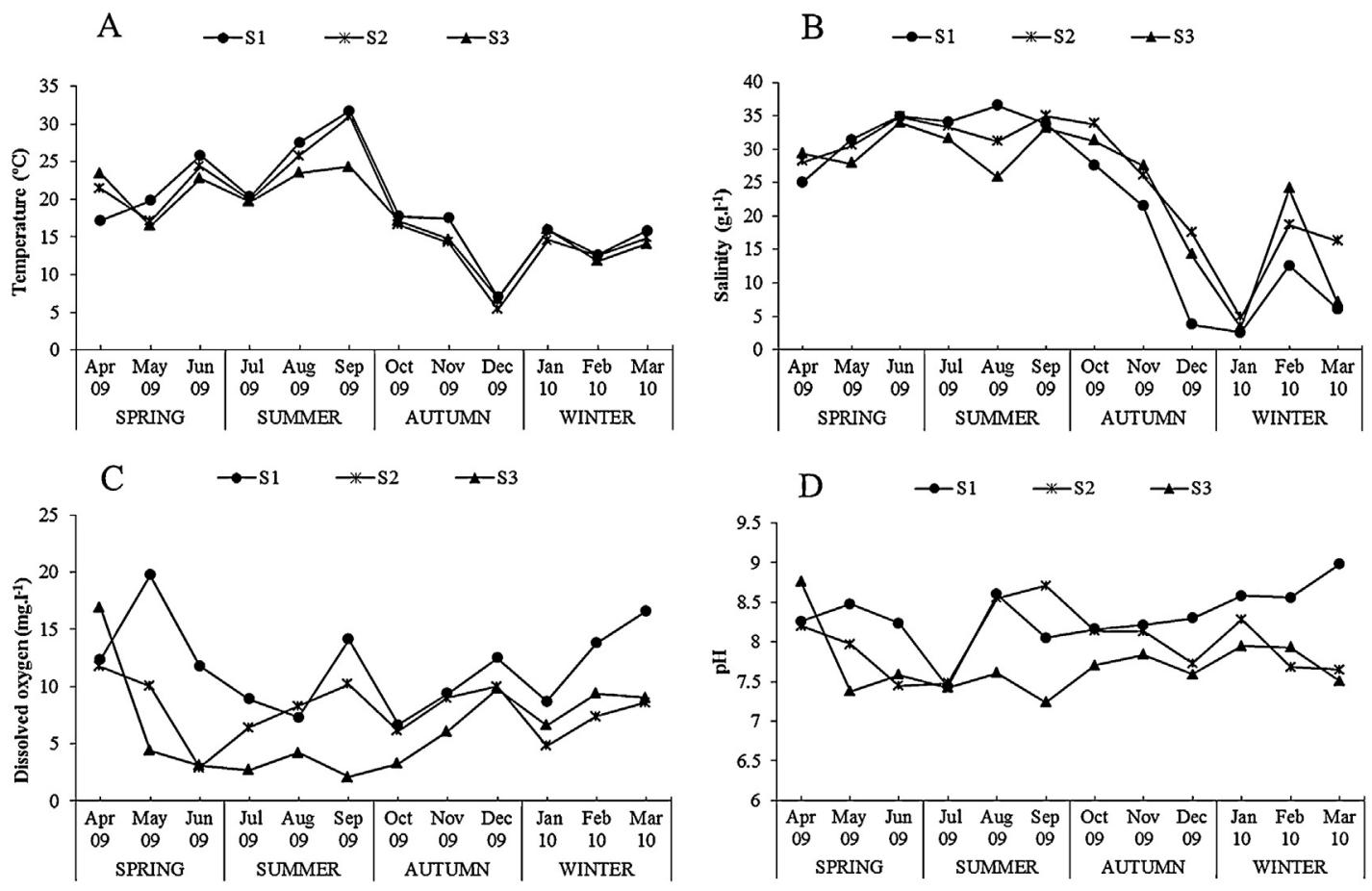

Fig. 5. Variation of the physicochemical parameters in the Mondego estuary over the study period: A, temperature; B, salinity; C, dissolved oxygen; D, pH.

the values from the 1980 s work $\left(6.36-8.81 \mathrm{~g} \mathrm{AFDW} \mathrm{m}^{-2} \mathrm{y}^{-1}\right)$, however, $P / \bar{B}$ ranges from our study (5.02-8.82) were higher than both the 1980 s and 1990 s studies (6.08-6.31 and 4.14-6.36, respectively).

Some population parameters were the same in all three studies, such as the multivoltine life cycle and the continuous reproduction. Sex-ratio was also different between decades, favouring females in the 1980s work and males in the 1990s and current study.

Regarding the variables that most influenced E. marinus, in the 1980s study, temperature and dissolved oxygen were positively correlated with density; fecundity was positively linked to temperature and salinity and negatively to phosphate concentration, while sex-ratio was positively influenced by dissolved oxygen and negatively by nitrite concentration. In the 1990s work, temperature and salinity were negatively correlated to density but only in the North arm (S1), whereas green macroalgae biomass had a positive effect on both density and biomass. In the present study, density was positively related to salinity and dissolved oxygen and negatively to ammonia and phosphate concentrations, while biomass was positively affected by salinity and negatively by ammonia concentrations.

Table 2

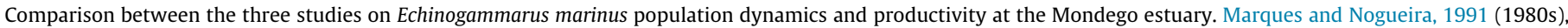
Maranhão et al., 2001 (1990s) and present study (2009-2010).

\begin{tabular}{|c|c|c|c|}
\hline & $1980 \mathrm{~s}$ & $1990 s$ & 2009-2010 \\
\hline Sampling periodicity & Monthly & Fortnightly & Monthly \\
\hline \multirow[t]{3}{*}{ Sampling stations } & Gala (St1); & Fontela; & Fontela (S1); \\
\hline & Armazéns (St2); & Armazéns; & Armazéns (S2); \\
\hline & Pranto (St3) & Pranto & Pranto (S3) \\
\hline Density & $500-4000$ & $25-700$ & $40-1400$ \\
\hline Reproduction & Continuous & Continuous & Continuous \\
\hline Recruitment & Discontinuous & Continuous & Continuous \\
\hline Life cycle & Multivoltine & Multivoltine & Multivoltine \\
\hline Sex-ratio & Female & Male & Male \\
\hline \multirow[t]{5}{*}{ Variables affecting E. marinus* } & Temperature $(+\mathrm{D}, \mathrm{F})$; & Temperature $(-\mathrm{D}, \mathrm{B})$; & Salinity (+D, B); \\
\hline & Dissolved $\mathrm{O}_{2}(+\mathrm{D}, \mathrm{S})$ & Salinity (-D); & Dissolved $\mathrm{O}_{2}(+\mathrm{D})$ \\
\hline & Salinity $(+F)$ & Green Macroalgae Biomass & Ammonia (-D, B); \\
\hline & Phosphate $(-\mathrm{F})$; & $(+D, B)$ & Phosphate(+D) \\
\hline & Nitrite $(-S)$ & & \\
\hline Production & $6.36-8.81$ & $1.74-5.38$ & $2.11-6.35$ \\
\hline$P / \bar{B}$ ratios & $6.08-6.31$ & $4.14-6.36$ & $5.02-8.82$ \\
\hline \multirow[t]{4}{*}{ Ecological condition } & Pre-eutrophic; & Eutrophic; & Post-mitigation; \\
\hline & No macroalgae blooms; & Massive green macroalgae & No significant macroalgae \\
\hline & Healthy seagrass beds & blooms; & blooms; \\
\hline & & Decrease in seagrass area & Recovery of seagrass beds; \\
\hline
\end{tabular}

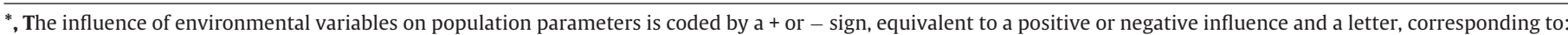
D, Density; B, Biomass; S, Sex-ratio; F, Fecundity. 


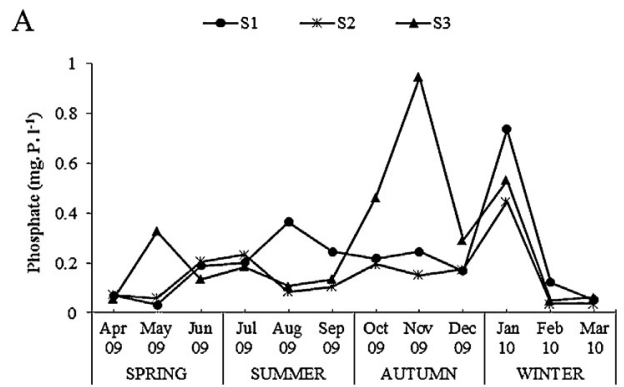

$\mathrm{C}$

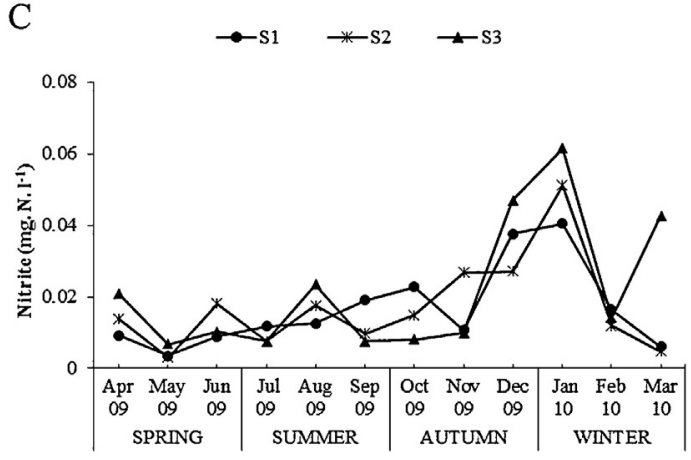

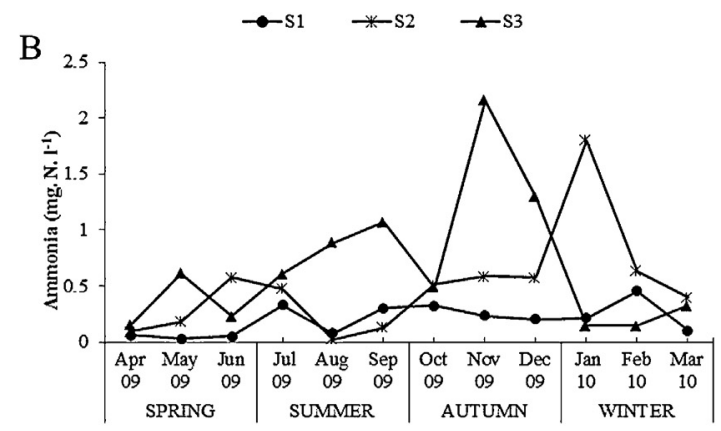

$\mathrm{D}$

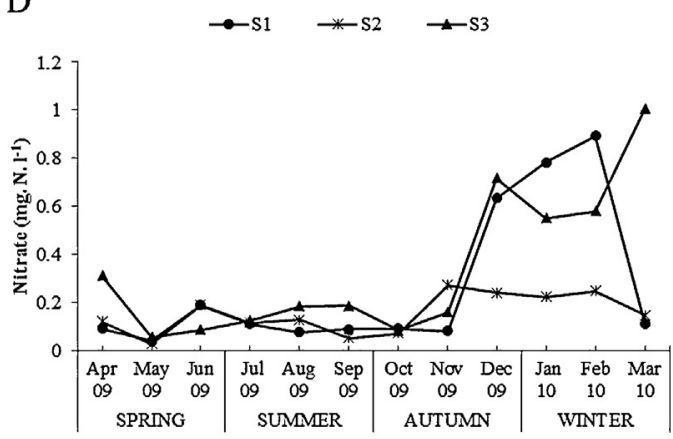

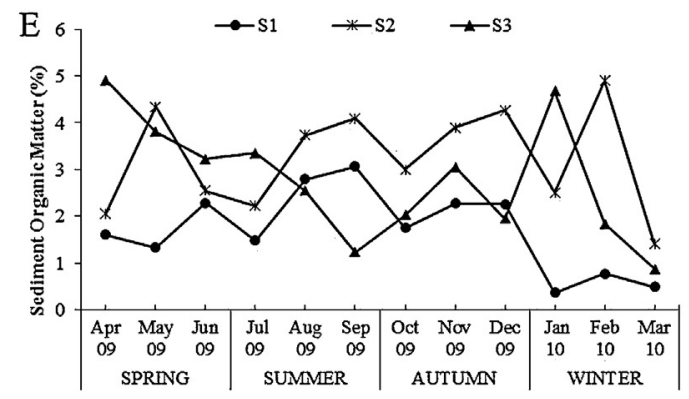

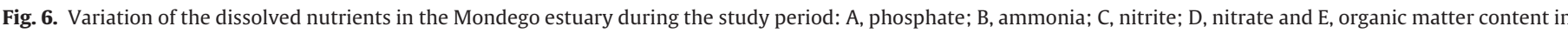
the sediment.

\section{Discussion}

\subsection{Density, biomass and environmental factors}

E. marinus density presented clear spatial and seasonal variations. Spatially, S1 (North arm) registered the highest values of density and S3 (South arm) the lowest, although differences between sampling stations were not statistically significant. These results differ from the ones obtained in the 1990s study (Maranhão et al., 2001), when the system was highly eutrophic and where S3 presented higher densities than S1. In the study carried out in the 1980s (Marques and Nogueira, 1991), before eutrophication symptoms were observed in the estuary, the authors also found high densities in S3, even though the highest values were recorded in S2 (South arm). Both studies suggested a possible upstream migratory pattern, in order to avoid unfavourable conditions during the wash out of wastewaters in S2, although it could not be proven. Maranhão et al. (2001) also proposed that the high organic content of the sediment favoured higher densities of E. marinus at S3, still no correlation was found between density and organic matter content in this study.

Regarding seasonal variation, as expected, spring presented the highest density values followed by a significant decrease, especially in S3, and a slight recovery in autumn at S2 and S1. By the end of the study period, $E$ marinus densities had reached very low values in all sampling stations due to a decrease in recruitment that occurred during colder months as a function of less favourable external conditions, namely, temperature (Maranhão et al., 2001). This pattern of seasonal variation of density is in agreement with other studies on E. marinus populations (Marques and Nogueira, 1991; Maranhão et al., 2001).

The environmental variables that best explained the density variability were salinity, dissolved oxygen, ammonia concentration and phosphate concentration, with a stronger positive influence of salinity and dissolved oxygen over the observed variation, while ammonia had a negative influence. Phosphate concentration also had a positive contribution but not as strong as the other variables.

In aqueous solution, ammonia can exist in the ionized form $\left(\mathrm{NH}_{4}{ }^{+}\right)$and unionized $\left(\mathrm{NH}_{3}\right)$, with the latter considered more toxic (Russo, 1985). In penaeids prolonged exposure to the toxic form of ammonia can result in the deterioration of physiological functions such as low growth rates and reproductive capacity, harmful changes in tissue structure and osmoregulation (Colt and Armstrong, 1981; Russo, 1985). In our study, ammonia concentrations were generally higher in S3, which may be related to the lower densities found in this sampling site. Nitrite and nitrate concentrations, although statistically non-significant, were also more elevated in S2 and S3 during winter, corresponding to a period of increased precipitation which generally leads to the wash-out of nutrient enriched water from the upstream agricultural fields.

Salinity was previously considered as a key factor affecting the population dynamics of E. marinus, through its effects on moulting 

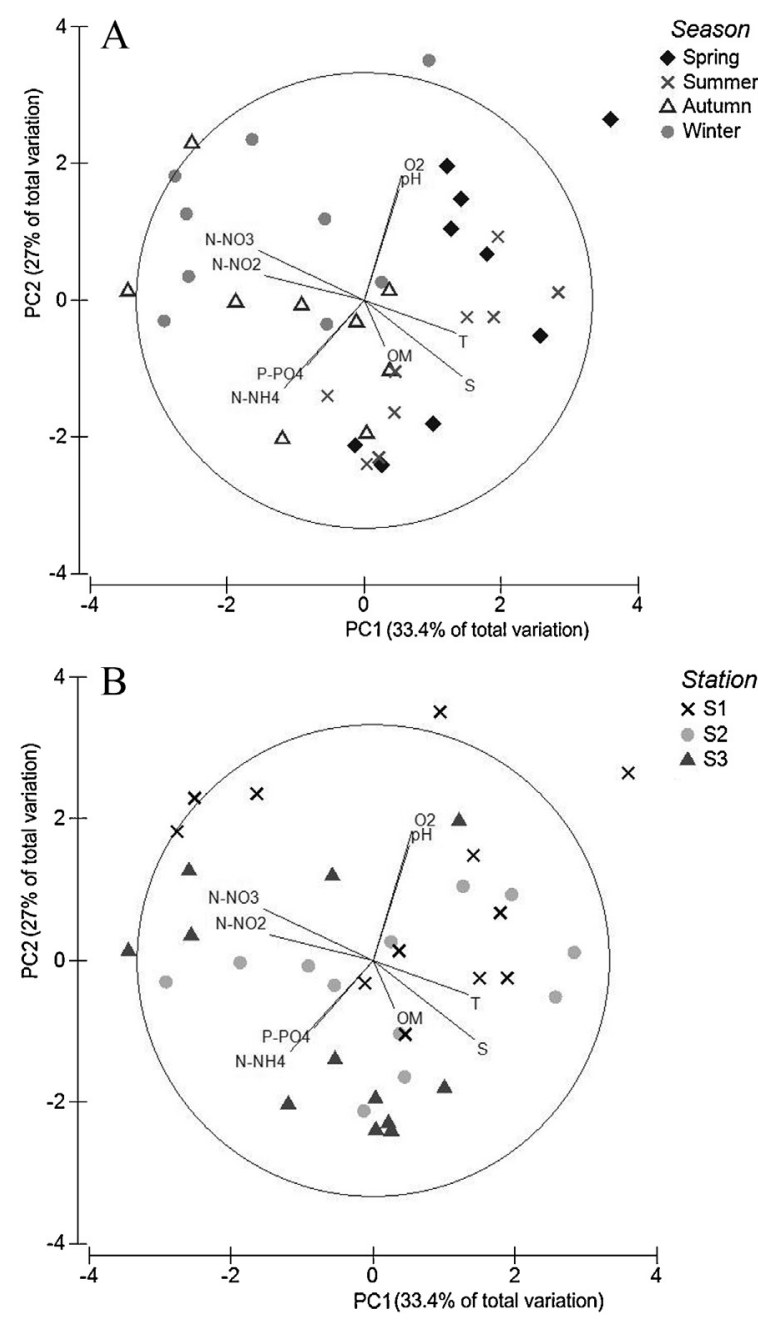

Fig. 7. PCA analysis of the abiotic variables in relation to season and station. (Axis $1=33.4 \%$ of total variation; Axis $2=27 \%$ of total variation). S, salinity; $T$, temperature;

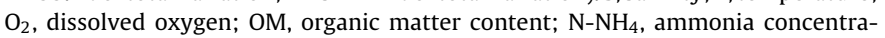
tion, $\mathrm{N}-\mathrm{NO}_{2}$, nitrite concentration; $\mathrm{N}-\mathrm{NO}_{3}$, nitrate concentration, $\mathrm{P}-\mathrm{PO}_{4}$, phosphate concentration: A, season; B, station.

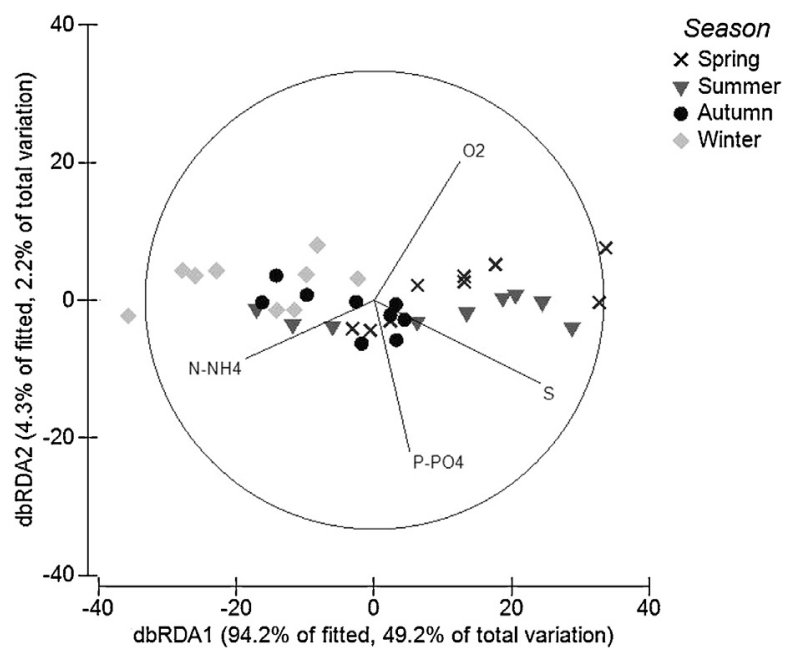

Fig. 8. dbRDA plot of the DistLM analysis representing the main variables that explain the density variation. $\mathrm{S}$, salinity, $\mathrm{O}_{2}$, dissolved oxygen, $\mathrm{P}^{-} \mathrm{PO}_{4}$, phosphate concentration and $\mathrm{N}-\mathrm{NH}_{4}$, ammonia concentration. and reproductive success, and in the Mondego estuary this species occurs within a range of 4-31 ppm (Marques and Nogueira, 1991; Maranhão et al., 2001; Maranhão and Marques, 2003). In our study salinity presented higher values during spring and summer, corresponding to the spring period of higher abundances in all sampling stations.

In the 1980s study, dissolved oxygen concentration was found to have a positive correlation with density as well as with sex-ratio. In the present study, oxygen concentration was higher in S1 and lower in S3, which could explain the higher and lower densities observed in those stations, respectively. Moreover, sex-ratio was predominantly male in S1, however no correlation was found between these parameters.

Regarding phosphate concentration, the 1980s study reported a negative correlation between this parameter and the number of eggs in ovigerous females, therefore affecting fecundity, and indirectly density. However, our results suggest a positive contribution of phosphate concentration over density, especially during spring and summer, yet the mechanisms of such interaction remain unclear.

The range of density variation of $E$. marinus observed in this study (100-1400 ind $\mathrm{m}^{-2}$ ) was higher than the one observed during the highly eutrophic period study (18-613 ind $\mathrm{m}^{-2}$, Maranhão et al., 2001) but still far from the range described in the noneutrophic period (96-3921 ind $\mathrm{m}^{-2}$, Marques and Nogueira, 1991), which might indicate that the system is recovering from the most ecologically critic period of the 1990s, when significant opportunistic algae blooms were observed (Flindt et al., 1997; Marques et al., 1997, 2003; Martins et al., 2001). In fact, other studies reported a positive response of several key species in the Mondego estuary, such as H. ulvae, $H$. diversicolor and S. plana, in a post-management period (Verdelhos et al., 2005; Dolbeth et al., 2007; Cardoso et al., 2010). However, our results seem to indicate that regarding E. marinus, density values are still lower than the ones reported in the 1980 s, which might indicate that the system is still recovering or under incomplete resilience (Borja et al., 2010).

Biomass values obtained in this study $\left(0.42-0.72 \mathrm{~g} \mathrm{AFDW} \mathrm{m}^{-2}\right.$ ) were lower approximately similar to the ones estimated by Maranhão et al. (2001) in the 1990s (0.39-0.86 AFDW m $^{-2}$ ) but lower than the ones recorded in the 1980s by Marques and Nogueira (1991) (1.01-1.45 $\mathrm{g} \mathrm{AFDW}^{-2}$ ), probably meaning that the population is still in a recovery phase.

Considering the population structure, in the present study E. marinus populations were generally dominated by juveniles, although during winter they presented similar densities to that of males and females, probably as the result of exposure to more harsh conditions. The previous studies on E. marinus populations in the Mondego estuary reported a juvenile dominance over 50\% (Marques and Nogueira, 1991; Maranhão et al., 2001), which was, apart from February and March 2010, the general pattern also observed in this study.

\subsection{Reproduction and sex-ratio}

As a whole, results indicate that in the Mondego estuary E. marinus presents continuous sexual activity and recruitment throughout the year. However, reproduction almost ceased during winter in S1 and by the end of this season in S3. Vlasblom and Bolier (1971) described lower viability of E. marinus eggs in the presence of low salinities, which might explain the decrease in the percentage of ovigerous females in S1 and S3, since lower salinity values were registered during winter at these stations $(7.1 \pm 5.1$ and $11.43 \pm 11.04$, respectively). A similar pattern was observed in the 1980s (Marques and Nogueira, 1991) and 1990s study (Maranhão et al., 2001), when very low percentages of ovigerous females occurred in association with low salinity values recorded 
in the same period of the year. Moreover, in the 1980s study, a positive correlation between salinity and percentage of ovigerous females and between temperature and percentage of juveniles was observed, indicating that temperature and salinity are key variables influencing sexual activity and, consequently, recruitment of E. marinus.

Sex-ratio presented considerable oscillations throughout the year in the studied population, nevertheless, a predominance of males was observed, except at $\mathrm{S} 1$ from midsummer to early autumn and at S3 by the end of autumn and late winter. A male predominance was also reported in the 1990s study (Maranhão et al., 2001) but not in the 1980s study, when Marques and Nogueira (1991) reported a female dominance, which seems to be the most common situation in E. marinus populations (Skadsheim, 1984). In the present study, no correlation was found between sex-ratio and the environmental variables monitored, while Marques and Nogueira (1991) found it positively correlated with dissolved oxygen and negatively with nitrate concentration in the water, and Maranhão et al. (2001) observed positive correlations with temperature and green macroalgae biomass. Several processes and variables, such as growth, maturation, longevity, predation rates (Beare and Moore, 1996) and photoperiod (Watt, 1994) appear also able to affect sexratio. Furthermore, microsporidean parasitism and intersexuality can influence sex-ratio in E. marinus populations (Ford et al., 2006; Martins et al., 2009), yet no evidence of such conditions were found in the present study.

\subsection{Production}

Production estimates showed spatial variations, with S2 presenting the highest annual production (6.35 $\mathrm{gAFDW} \mathrm{m}^{-2} \mathrm{y}^{-1}$ ), closely followed by S1 (5.78 $\left.\mathrm{gAFDW} \mathrm{m} \mathrm{A}^{-2} \mathrm{y}^{-1}\right)$. These two stations also presented higher average annual biomass and very similar $P / \bar{B}$ ratios, as well as being the stations with higher densities and biomass values, which contributed to a higher production. S3, on the other hand, displayed the lowest values of annual production $\left(2.11 \mathrm{~g} \mathrm{AFDW}^{-2} \mathrm{y}^{-1}\right)$, average annual biomass and $P / \bar{B}$ ratios, which were related to lower densities and biomasses.

Considering E. marinus production values reported in previous studies, the present values (2.11-6.35 $\left.\mathrm{g} \mathrm{AFDW} \mathrm{m}^{-2} \mathrm{y}^{-1}\right)$ are higher than those observed during the 1990s (1.74-5.38 $\mathrm{g} \mathrm{AFDW} \mathrm{m}^{-2} \mathrm{y}^{-1}$ ), when the system was strongly eutrophic but lower than the values registered in the $1980 \mathrm{~s}\left(6.36-8.80 \mathrm{~g} \mathrm{AFDW} \mathrm{m}^{-2} \mathrm{y}^{-1}\right)$, before the system became strongly eutrophic. This may be related to the general improvement of the system from 2000, following the implementation of mitigation measures (Cardoso et al., 2005; Lillebø et al., 2005; Verdelhos et al., 2005).

E. marinus $P / \bar{B}$ ratios in the present study ranged between 5.02 and 8.82 , contrasting with values ranging from 6.08 to 6.31 in the 1980 s and $4.14-6.56$ in the 1990 s. Such differences may reflect the response to different levels of stress occurred during the last three decades, since biomass accumulation tends to decrease as organisms cope with the system disturbance, resulting in increased $P / \bar{B}$ ratios and indicating a low efficiency of converting energy to organic structure (Odum, 1985).

Variations in production and $P / \bar{B}$ ratios through long term periods allow an increase in the level of understanding of the system functioning (Dolbeth et al., 2007, 2011), and again our results suggest that the Mondego estuary is a resilient system, but has not yet recovered the conditions that prevailed before the system became highly eutrophic.

\section{Conclusions}

Despite the fact that Echinogammarus marinus population's density, biomass, and $P / \bar{B}$ ratios exhibited clear seasonal and spatial variations in the Mondego estuary, results from the present and previous studies, all together covering a 30 years period, indicate that the system is gradually recovering from the strongly eutrophic situation that occurred in the 1990s. Nevertheless, results clearly suggest that recovery is still incomplete if we consider the population parameters reported during the 1980s, when eutrophication symptoms were not evident. Further monitoring of this species production values and $P / \bar{B}$ ratios will be able reveal if the system will return to the pre-existing condition, observed in the 1980 s, or will remain under incomplete resilience.

\section{Acknowledgments}

This study was carried using means provided by the research projects RECONNECT (PTDC/MAR/64627/2006), EXTREMIS (III/36/2008), WISER (FP7-ENV-2008-226273), 3M-RECITAL (LTER/BIA-BEC/0019/2009) and INPACTAR (PTDC/MAR/111537/2009). It was also subsidized by the European Social Fund and MCTES National Funds, through the POPH (Human Potential Operational Programme) - NSRF (National Strategic Reference Framework-4.4), QREN (Quadro de Referência Estratégica Nacional), Ciência 2007 and COMPETE. The authors also thank all the colleagues who assisted in the field and laboratory work.

\section{References}

Adger, W.N., 2000. Social and ecological resilience: are they related? Prog. Hum. Geog. 24, 347-364.

Anderson, M., Clarke, K., Gorley, R., 2008. PERMANOVA+ for Primer: Guide to Software and Statistical Methods. University of Auckland and PRIMER-E Ltd Plymouth, UK.

Beare, D.J., Moore, P.G., 1996. The distribution, growth and reproduction of Pontocrates arenarius and P. altamarinus (Crustacea Amphipoda) at Millport, Scotland. J. Mar. Biol. Assoc. U.K. 76, 931-950.

Borja, Á., Dauer, D.M., Elliott, M., Simenstad, C.A., 2010. Medium- and long-term recovery of estuarine and coastal ecosystems: patterns, rates and restoration effectiveness. Estuar. Coast. 33, 1249-1260.

Cardoso, P.G., Pardal, M.A., Lillebø, A.I., Ferreira, S.M., Raffaelli, D., Marques, J.C., 2004 Dynamic changes in seagrass assemblages under eutrophication and implications for recovery. J. Exp. Mar. Biol. Ecol. 302, 233-248.

Cardoso, P.G., Brandão, A., Pardal, M.A., Raffaelli, D., Marques, J.C., 2005. Resilience of Hydrobia ulvae populations to anthropogenic and natural disturbances. Mar Ecol. Prog. Ser. 289, 191-199.

Cardoso, P.G., Raffaelli, D., Lillebø, A.I., Verdelhos, T., Pardal, M.A., 2008a. The impact of extreme flooding events and anthropogenic stressors on the macrobenthic communities' dynamics. Estuar. Coast. Shelf Sci. 76, 553-565.

Cardoso, P.G., Raffaelli, D., Pardal, M.A., 2008b. The impact of extreme weather events on the seagrass Zostera noltii and related Hydrobia ulvae population. Mar. Pollut. Bull. 56, 483-492.

Cardoso, P.G., Leston, S., Grilo, T.F., Bordalo, M.D., Crespo, D., Raffaelli, D., Pardal, M.A. 2010. Implications of nutrient decline in the seagrass ecosystem success. Mar. Pollut. Bull. 60, 601-608.

Clarke, K.R., Warwick, R.M., 2001. Changes in Marine Communities: An Approach to Statistical Analysis and Interpretation, Second ed. Primer-E, Plymouth.

Colt, J.E., Armstrong, D.A., 1981. Nitrogen toxicity to crustaceans, fish, and molluscs. In: Allen, J.L., Kinney, E.C. (Eds.), Proceedings of the Bio-Engineering Symposium for Fish Culture. Fish Culture Section American Fisheries Society, Northeast Society of Conservation Engineers. Maryland, Bethesda, pp. 34-47.

Costanza, R., Kemp, M., Boynton, W., 1995. Predictability, scale, and biodiversity in coastal and estuarine ecosystems: implications for management. In: Perrings, C.A., Mäler, K.-G., Folke, C., Holling, C.S., Jansson, B.-O. (Eds.), Biodiversity Loss: Economic and Ecological Issues. Cambridge University Press, Cambridge, pp. 84-125.

Dolbeth, M., Pardal, M.A., Lillebø, A.I., Azeiteiro, U., Marques, J.C., 2003. Short- and long-term effects of eutrophication on the secondary production of an intertidal macrobenthic community. Mar. Biol. 143, 1229-1238.

Dolbeth, M., Cardoso, P.G., Ferreira, S.M., Verdelhos, T., Raffaelli, D., Pardal, M.A. 2007. Anthropogenic and natural disturbance effects on a macrobenthic estuarine community over a 10-year period. Mar. Pollut. Bull. 54, 576-585.

Dolbeth, M., Cardoso, P.G., Grilo, T.F., Bordalo, M.D., Raffaelli, D., Pardal, M.A., 2011 Long-term changes in the production by estuarine macrobenthos affected by multiple stressors. Estuar. Coast. Shelf Sci. 92, 10-18.

Duarte, A.A., Pinho, J.L., Pardal, M.A., Vieira, J.M., Santos, F.S., 2001. Effect of residence times on River Mondego estuary eutrophication vulnerability. Water Sci. Technol. 44 (2-3), 329-336.

Elliott, M., Quintino, V., 2007. The estuarine quality paradox, environmental homeostasis and the difficulty of detecting anthropogenic stress in naturally stressed areas. Mar. Pollut. Bull. 54, 640-645. 
Elliott, M., Burdon, D., Hemingway, K.L., Apitz, S.E., 2007. Estuarine, coastal and marine ecosystem restoration, confusing management and science-a revision of concepts. Estuar. Coast. Shelf Sci. 74, 349-366.

Flindt, M.R., Kamp-Nielsen, L., Marques, J., Pardal, M., Bocci, M., Bendoricchio, G., Salomonsen, J., Nielsen, S., Jørgensen, S., 1997. Description of the three shallow estuaries, Mondego River (Portugal), Roskilde Fjord (Denmark) and the lagoon of Venice (Italy). Ecol. Model. 102, 17-31.

Ford, A.T., Fernandes, T.F., Robinson, C.D., Davies, I.M., Read, P.A., 2006. Can industrial pollution cause intersexuality in the amphipod, Echinogammarus marinus? Mar. Pollut. Bull. 53, 100-106.

Grémare, A., Marsh, A., Tenore, K., 1989. Secondary production and reproduction of Capitella capitata type I (Annelida, Polychaeta) during a population cycle. Mar. Ecol. Prog. Ser. 51, 99-105.

Hernandez, I., Peralta, G., Perez-Llorens, J.L., Vergara, J.J., Niell, F.X., 1997. Biomass and dynamics of growth of ulva species in Palmones River Estuary. J. Phycol. 33, 764-772.

Holling, C.S., Schindler, D.W., Walker, B.W., Roughgarden, J., 1995. Biodiversity in the functioning of ecosystems: an ecological primer and synthesis. In: Perrings, C., Mäler, K.-G., Folke, C., Holling, C.S., Jansson, B.-O. (Eds.), Biodiversity Loss: Ecological and Economics Issues. Cambridge University Press, Cambridge, pp. 44-83.

Kemp, W.M., Boynton, W.R., Adolf, J.E., Boesch, D.F., Boicourt, W.C., Brush, G., Cornwell, J.C., Fisher, T.R., Glibert, P.M., Hagy, J.D., Harding, L.W., Houde, E.D., Kimmel, D.G., Miller, W.D., Newell, R.I.E., Roman, M.R., Smith, E.M., Stevenson, J.C., 2005. Eutrophication of Chesapeake Bay: historical trends and ecological interactions. Mar. Ecol. Prog. Ser. 303, 1-29.

Krueger, C.C., Martin, F.B., 1980. Computation of confidence intervals for the size-frequency (Hynes) method of estimating secondary production. Limnol. Oceanogr., 773-777.

Lillebø, A.I., Pardal, M.Â., Marques, J.C., 1999. Population structure, dynamics and production of Hydrobia ulvae (Pennant) (Mollusca Prosobranchia) along an eutrophication gradient in the Mondego estuary (Portugal). Acta Oecol. 20, 289-304.

Lillebø, A.I., Neto, J.M., Martins, I., Verdelhos, T., Leston, S., Cardoso, P.G., Ferreira, S.M., Marques, J.C., Pardal, M.A., 2005. Management of a shallow temperate estuary to control eutrophication: the effect of hydrodynamics on the system's nutrient loading. Estuar. Coast. Shelf Sci. 65, 697-707.

Limnologisk Metodik, 1992. Ferskvandsbiologisk Laboratorium. Københavns Universitet, Akademisk Forlag, København, 172 pp.

Maranhão, P., Bengala, N., Pardal, M., Marques, J.C., 2001. The influence of environmental factors on the population dynamics, reproductive biology and productivity of Echinogammarus marinus Leach (Amphipoda, Gammaridae) in the Mondego estuary (Portugal). Acta Oecol. 22, 139-152.

Maranhão, P., Marques, J.C., 2003. The influence of temperature and salinity on the duration of embryonic development, fecundity and growth of the amphipod Echinogammarus marinus Leach (Gammaridae). Acta Oecol. 24, 5-13.

Maren, M.J., 1975a. Some notes on the intertidal gammarids (Crustacea, Amphipoda) from the Atlantic coast of the Iberian Peninsula. Beaufortia 23, 153-168.

Maren, M.J., 1975b. The biology of Chaetogammarus marinus (Leach) and Eulimnogammarus obtusatus (Dahl), with some notes on other intertidal gammarid species (Crustacea, Amphipoda). Bijdr. Dierk 45, 204-224.

MarLIN Glossary, 2005. The Marine Life Information Network for Britain and Ireland: Online Glossary of Scientific Terms, Available from http://www.marlin.ac.uk/glossary.php

Marques, J.C., Nogueira, A., 1991. Life cycle, dynamics and production of Echinogammarus marinus (Leach; Amphipoda) in the Mondego estuary (Portugal). Oceanol. Acta 14, 213-213.

Marques, J.C., Bellan-Santini, D., 1993. Biodiversity in the ecosystem of the Portuguese continental shelf: distributional ecology and the role of benthic amphipods. Mar. Biol. 115, 555-564.

Marques, J.C., Maranhão, P., Pardal, M.A., 1993a. Human impact assessment on the subtidal macrobenthic community structure in the Mondego Estuary (Western Portugal). Estuar. Coast. Shelf Sci. 37, 403-419.
Marques, J.C., Rodrigues, L.B., Nogueira, A.J.A., 1993b. Intertidal macrobenthic communities structure in the Mondego estuary (Western Portugal): reference situation. Vie Milieu 43, 177-187.

Marques, J.C., Pardal, M.A., Nielsen, S.N., Jørgensen, S.E., 1997. Analysis of the properties of exergy and biodiversity along an estuarine gradient of eutrophication. Ecol. Model. 102, 155-167.

Marques, J.C., Nielsen, S.N., Pardal, M.A., Jørgensen, S.E., 2003. Impact of eutrophication and river management within a framework of ecosystem theories. Ecol. Model. 166, 147-168.

Marques, L., Carriço, A., Bessa, F., Gaspar, R., Neto, J.M., Patrício, J., 2013. Response of intertidal macrobenthic communities and primary producers to mitigation measures in a temperate estuary. Ecol. Indicators 25, $10-22$.

Marques, S.C., Pardal, M.A., Pereira, M.J., Gonçalves, F., Marques, J.C., Azeiteiro, U.M., 2007. Zooplankton distribution and dynamics in a temperate shallow estuary. Hydrobiologia 587, 213-223

Martins, I., Pardal, M.Â., Lillebø, A.I., Flindt, M.R., Marques, J.C., 2001. Hydrodynamics as a major factor controlling the occurrence of green macroalgal blooms in a Eutrophic Estuary: a case study on the influence of precipitation and river management. Estuar. Coast. Shelf Sci. 52, 165-177.

Martins, I., Ford, A.T., Fernandes, T.F., 2009. Intersexuality incidence, sex ratio fluctuations and intersex reproductive output as factors affecting the temporal variation of intersexed populations of the marine amphipod Echinogammarus marinus. Mar. Environ. Res. 68, 163-169.

Múrias, T., Cabral, J.A., Marques, J.C., Goss-Custard, J.D., 1996. Short-term effects of intertidal macroalgal blooms on the macrohabitat selection and feeding behaviour of wading birds in the Mondego Estuary (West Portugal). Estuar. Coast. Shelf Sci. 43, 677-688.

Múrias, T., Cabral, J.A., Lopes, R., Marques, J.C., 1997. Low-water use of the Mondego estuary (West Portugal) by waders (Charadrii). Ardeola 44 79-91.

Neto, J.M., Teixeira, H., Patrício, J., Baeta, A., Veríssimo, H., Pinto, R., Marques, J.C., 2010. The response of estuarine macrobenthic communities to natural- and human-induced changes: dynamics and ecological quality. Estuar. Coast. 33 $1327-1339$.

Odum, E.P., 1985. Trends expected in stressed ecosystems. Bioscience 35, 419-422.

Pimm, S.L., 1984. The complexity and stability of ecosystems. Nature 307, 321-326.

Pinto, R., Patrício, J., Neto, J.M., Salas, F., Marques, J.C., 2010. Assessing estuarine quality under the ecosystem services scope: ecological and socioeconomic aspects. Ecol. Complex. 7, 389-402.

Russo, R.C., 1985. Ammonia, nitrite and nitrate. In: Rand, G.M., Petrocelli, S.R. (Eds.), Fundamentals of Aquatic Toxicology. Hemisphere Publishing Corporation, Washington DC, pp. 455-471.

SER, 2002. Society for ecological restoration international science and policy working group, 2004. In: The SER International Primer on Ecological Restoration. Society for Ecological Restoration International, Tucson http://www.ser.org

Skadsheim, A., 1984. Life cycles of Gammarus oceanicus and G. salinus (Amphipoda) in the Oslofjord, Norway. Ecography 7, 262-270.

Strickland, J., Parsons, T., 1972. A Practical Handbook of Seawater Analysis. Fisheries Research Board, Canada.

Verdelhos, T., Neto, J.M., Marques, J.C., Pardal, M.A., 2005. The effect of eutrophication abatement on the bivalve Scrobicularia plana. Estuar. Coast. Shelf Sci. 63, $261-268$.

Veríssimo, H., Neto, J.M., Teixeira, H., Franco, J.N., Fath, B.D., Marques, J.C., Patrício, J., 2012. Ability of benthic indicators to assess ecological quality in estuaries following management. Ecol. Indicators 19, 130-143.

Vlasblom, A.G., Bolier, G., 1971. Tolerance of embryos of Marinogammarus marinus and Orchestia gammarella (Amphipoda) to lowered salinities. Neth. J. Sea Res. 5 334-341.

Watt, P.J., 1994. Parental control of sex ratio in Gammarus duebeni, an organism with environmental sex determination. J. Evol. Biol. 7, 177-187. 